\title{
Genome-Wide Mapping of Copy Number Variations Using SNP Arrays
}

\author{
Daniel Nowak $^{\mathrm{a}}$ Wolf-Karsten Hofmann ${ }^{\mathrm{b}}$ H. Phillip Koeffler ${ }^{\mathrm{a}}$ \\ ${ }^{\text {a }}$ Division of Hematology and Oncology, Cedars Sinai Medical Center, UCLA School of Medicine, Los Angeles, USA \\ ${ }^{b}$ Department of Hematology and Oncology, Hospital Mannheim, Germany
}

\section{Key Words \\ SNP array}

\section{Summary}

The availability of high-density single nucleotide polymorphism (SNP) microarrays in recent years has proven to be a great step forward in the context of global analysis of genomic abnormalities in disease. SNP arrays offer great robustness, high resolution and the possibility to detect a variety of different genomic copy number variations such as submicroscopic deletions, amplifications, loss of heterozygosity and uniparental disomy. Moreover, they can be used to perform genome-wide association studies. Therefore, SNP arrays harbor several advancements over traditional molecular methods to analyze genomic aberrations, such as cytogenetic analyses, fluorescence in situ hybridization or comparative genomic hybridization methods. Until now, SNP arrays have exclusively been used in experimental research and have enabled seminal new discoveries in many fields by identifying common genomic lesions underlying specific diseases, especially cancer. However, it is foreseeable that SNP arrays will also take up a position in routine diagnostic processes in the future. This review focuses on technical principles of the SNP array technology and their utilization to detect submicroscopic genomic and polymorphic markers associated with disease.

\author{
Schlüsselwörter \\ SNP-Array
}

\section{Zusammenfassung:}

Die Einführung und Anwendung hochauflösender «Single nucleotide polymorphism»(SNP)-Microarrays zur Untersuchung genomischer Aberrationen hat sich in den letzten Jahren als großer Fortschritt für zahlreiche medizinische Forschungszweige erwiesen. Die Genomanalyse mittels SNP-Arrays ist eine einfache und robuste Methode, die in einem Untersuchungsgang die Detektion submikroskopischer genomischer Deletionen, Amplifikationen und uniparentalen Disomien in einer bisher unübertroffenen Auflösung ermöglicht. Darüber hinaus können über eine Genotypisierung hunderttausender Einzelbasenpolymorphismen erstmals genomweite Assoziationsstudien in größeren Populationen durchgeführt werden. Aufgrund dieser Eigenschaften bieten SNP-Arrays zahlreiche Vorteile gegenüber traditionellen molekulargenetischen Untersuchungsmethoden wie z.B. Metaphasenzytogenetik, Fluoreszenz-in-situ-Hybridisierung oder "comparative genomic hybridization". Bisher wurden SNP-Arrays ausschließlich in der experimentellen Forschung eingesetzt und haben dabei bahnbrechende Erfolge durch die Identifikation neuer, krankheitsspezifischer genomischer Veränderungen erzielt. Es ist jedoch abzusehen, dass SNPArrays aufgrund ihrer einfachen Anwendung und ihrer hohen Auflösung in Zukunft auch in diagnostischen Routineuntersuchungen eine Bedeutung bekommen werden. Diese Übersichtsarbeit beschreibt die technischen Prinzipien der SNP-Array-Technologie und ihre Anwendung zur Identifikation krankheitsspezifischer genomischer Polymorphismen und Aberrationen.

\begin{tabular}{ll}
\hline KARGER & @ 2009 S. Karger GmbH, Freiburg \\
Fax +497614520714 & Accessible online at: \\
Information@Karger.de & www.karger.com/tmh \\
www.karger.com &
\end{tabular}




\section{Principles of SNP Array Technology}

The most common source of genetic variation in the human genome is the existence of single base polymorphisms described as SNPs (single nucleotide polymorphisms). These are germline point mutations naturally and statistically occurring in the course of evolution. To be defined as a SNP, these polymorphisms must occur with a minor allele frequency of at least $1 \%$ in a given population. Approximately 15 million SNPs are dispersed throughout the human genome [1]. In the great majority, SNPs occur in two alleles, and if they lie in a coding region of a gene, they are distinguished into synonymous or non-synonymous SNPs depending on whether they do or do not change the amino acid sequence, respectively. But also SNPs lying in non-coding regions of the genome may have an impact on splicing processes or transcription factor binding and hence varying phenotypes.

The different alleles of SNPs can be interrogated by sequence-specific oligonucleotide microarrays. Similarly to the production of gene expression microarrays, sequence-specific oligonucleotides homologous to the different SNP alleles can be synthesized onto gene chips by photolithographic methods (Affymetrix, Santa Clara, CA, USA). For greater reliability, several different probes containing perfect matches and mismatches are combined for interrogation of a single SNP.

To be hybridized to these arrays, highly purified genomic DNA is processed by restriction enzymes followed by adaptor ligation and single primer PCR to produce a collection of PCR products with a selected size range. The PCR products are then fragmented and labeled with a fluorochrome. The labeled DNA fragments are subsequently hybridized to the array. Depending on their genotype, the fragments bind specifically to their corresponding perfect match probe, and binding can be measured by a scanner picking up the fluorescent signal on the array features (fig. 1). Modern arrays cover up to $1,800,000$ SNPs and non-polymorphic copy number markers on a single array and thereby reach a sub-mega base pair resolution with median inter-marker distances of as low as 700 bases.

The results of this measurement provide two different types of information. One is a data set comprising the intensity data of all SNPs. Since the human genome is diploid, the intensity values are raised to two after normalization, representing the normal copy number of alleles on somatic chromosomes. A homozygous deletion of genomic material results in a copy number value of zero and a heterozygous deletion in a copy number value of one (fig. 2A). Duplications or amplifications result in values of 3 or higher integer copy numbers, respectively (fig. 2B). This can be used to infer the copy number of any given genomic region containing the SNP or other marker sequences. In newer arrays also non-polymorphic genomic regions are interrogated in order to achieve a better coverage, because SNPs well suited for microarray analysis are not evenly distributed throughout the genome.
Apart from copy number data, the method also yields a genotype data set generated by the SNP calls of either AA, $\mathrm{AB}$ or BB standing for the alleles of the SNPs. This, combined with the copy number data, allows the detection of loss of heterozygosity (LOH) and, importantly, also copy number-neutral $\mathrm{LOH}$ in form of acquired uniparental disomy (aUPD) (fig. 2C) or homozygous DNA stretches caused by consanguinity [2]. aUPD represents an allelic imbalance when one allele is deleted and the other one is duplicated or amplified, leading to regions with homozygous SNP calls but a copy number of two or higher. Regions like this, similarly to regions of $\mathrm{LOH}$ caused by real deletions, are interesting in cancer research because they have a high probability of containing either a mutated tumor suppressor gene (TSG) or oncogene with loss of their normal allele. SNP arrays are unique in being able to detect these genomic lesions as compared to other cytogenetic methods, which are not able to detect this phenomenon.

In an ideal SNP array experiment to determine acquired genomic changes in a malignancy, the tumor sample is concomitantly analyzed with a matched normal sample of germline DNA from the same individual. This allows definitely to determine which lesions are newly acquired in the tumor sample as opposed to patterns already existing in the germline DNA such as copy number polymorphisms, which are widely distributed throughout human populations [3]. However, if matched normal samples are not available, computational probability algorithms can be used to infer LOH by using anonymous references [4-6], and these models reach an accuracy nearly equaling the power of analysis with matched normal samples. Furthermore, newer algorithms also allow an allele-specific copy number analysis, giving information about which specific parental allele is affected by a given aberration [5] (fig. 2A-C). When using anonymous references, possible copy number polymorphisms must be identified by comparing the tumor SNP chip data with registered copy number polymorphisms in the data bases of genome browsers. Similarly to gene expression microarray experiments, alterations detected by SNP arrays, which are hypothesized to have a pathologic impact, should be validated by alternative methods such as cytogenetic analyses, fluorescence in situ hybridization, quantitative real-time PCR of genomic DNA, direct sequencing of SNPs or microsatellite analysis.

\section{Detection of Genomic Aberrations using High-Density SNP Arrays}

Due to the high density of genome coverage provided by modern SNP arrays with median inter-SNP distances of $<0.7 \mathrm{~kb}$ their accuracy and resolution of whole genome screening for deletions, amplifications, $\mathrm{LOH}$ and aUPD is a great advancement over conventional cytogenetic and array-comparative genomic hybridization methods. These advantages have been particularly useful in cancer research where the increasing understanding of 
Fig. 1. Principles of Affymetrix SNP array technology. Genomic DNA is digested by restriction enzymes to form fragments of varying lengths. These are subjected to ligation with adapters to enable a one-primer PCR to produce fragments of selected size (200-1,100 bp). Subsequently, these are labeled with a fluorochrome and hybridized to the microarray. There, DNA fragments containing a SNP specifically bind to their allele-specific perfect match probes. The hybridized and washed array is then scanned by a laser, picking up fluorescent signals in dependency of quantitative binding. The raw data can be calculated into intensity data giving information about the DNA copy number, and determination of the SNP alleles provides information about the genotype.

genomic aberrations underlying specific malignancies is rapidly leading to improved classification and prognostic systems as well as identification of new targets for therapeutic intervention.

To this end, studies using SNP arrays have refined and added substantial new information about the genomic aberrations in a large variety of cancers such as hematologic malignancies [7-12] and solid tumors [13-17] in recent years. The strength of the method lies in the ability to narrow down with great resolution to candidate target genes by searching for common regions affected in a large number of samples. Often, the underlying lesion in cancer is a mutated TSG with concomitant loss of the non-mutated allele. Such mutated TSGs can therefore often be found in regions of heterozygous deletion or aUPD. When the region is very large, identifying the causative gene among hundreds of interesting candidate genes can be very difficult. However, by overviewing the composite SNP array data of many tumor samples of the same entity, the candidate gene may be isolated by narrowing the common region affected in all samples (fig. 3). For example, this could impressively be demon-
Genomic DNA
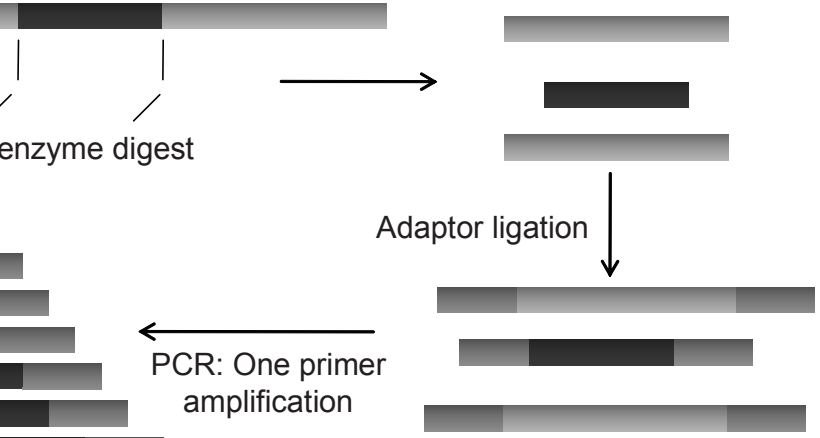
amplification
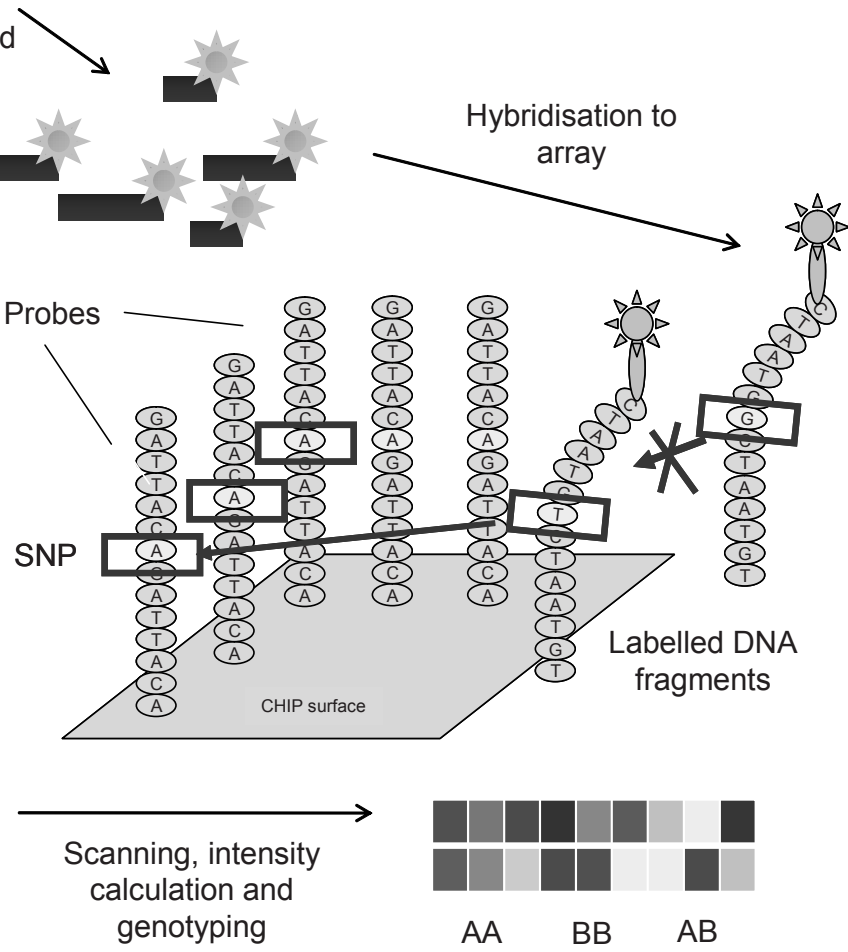

strated in SNP array analysis of acute lymphoblastic leukemia (ALL) where the B-cell specific transcription factor Pax5 was found to be the most frequent target of somatic mutation in ALL $[11,18]$ and the deletion of the transcription factor IKZF1 is a characteristic hallmark of BCR-ABL1-positive ALL [19]. The same is also true for the detection of amplified oncogenes, for example in prostate cancers and melanomas [20, 21]. The relevancy of mutated genes found in aUPD was demonstrated by the association of frequent aUPD and mutation of the janus kinase gene 2 (Jak2) as a characteristic lesion in myeloproliferative diseases [5, 22]. Another useful application of SNP arrays in cancer research is the identification of gene translocations and fusion products. While one of the few drawbacks of SNP array analysis is their inability to detect balanced translocations, it is a strong tool for the detection of breakpoints in unbalanced genomic translocations [12], which has led to the discovery of numerous new fusion products in leukemia [23].

In order to increase the accuracy in search for tumor-associated target genes even more, numerous investigators have com- 
Fig. 2. Genomic alterations detectable by SNP arrays, visualized with the CNAG (Copy Number Analyser for GeneChip ${ }^{\circledR}$ ) software and allele-specific copy number determination. A Deletions on chromosome 9 in an ALL sample: Hemizygous deletions are characterized by reduction of the copy number value from 2 to 1. This is evidenced by a downward deviation of the copy number signals of single SNPs (single dots in the upper line), the averaged copy number signal (continuous line in the second panel from above) and deletion of one allele as shown by downward deviation of one of the allele-specific copy number signals (two separate lines in the lower panel). In homozygous deletions, both alleles are deleted, and the copy number value is reduced to 0 . B Duplications and amplifications on chromosome 8q: Duplications are identified by an upward deviation of the copy number value to 3 (for duplications) or $>3$ for amplification of genomic material. C aUPD on chromosome 17q. aUPD is displayed by divergence of the allele-specific copy number signals in the lower panel. These indicate that one parental allele is duplicated while the other one is deleted. Throughout this region, the copy number value remains $=2$, but a $\mathrm{LOH}$ is evidenced by the drastic loss of heterozygous SNP calls (vertical lines below the cytoband), the remaining ones are erroneous SNP calls caused by contamination of the tumor sample with normal DNA.
A

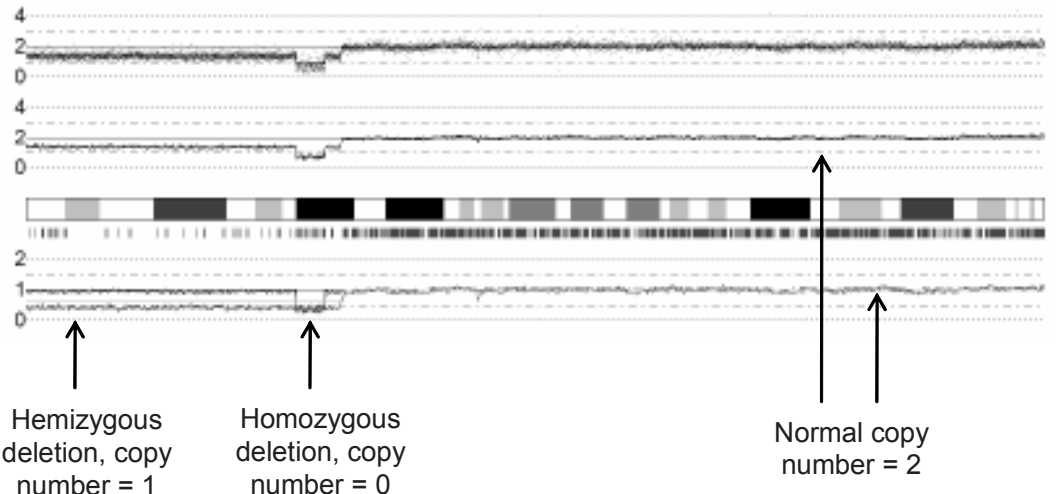

B

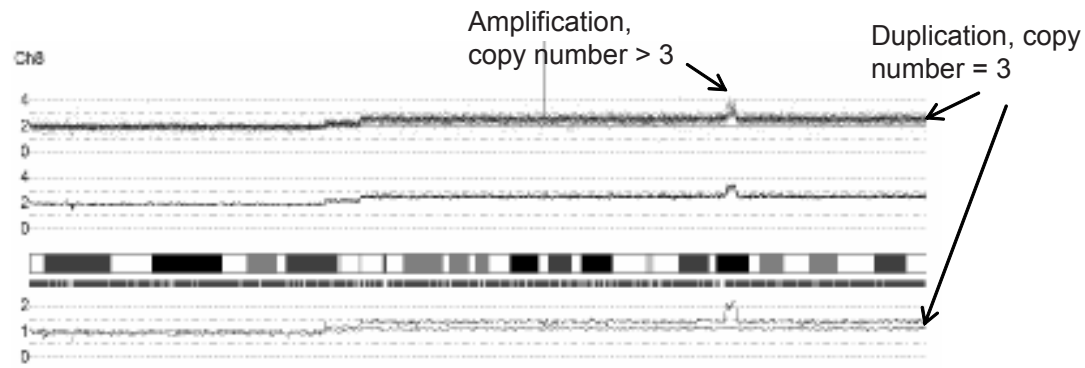

C

Ch17

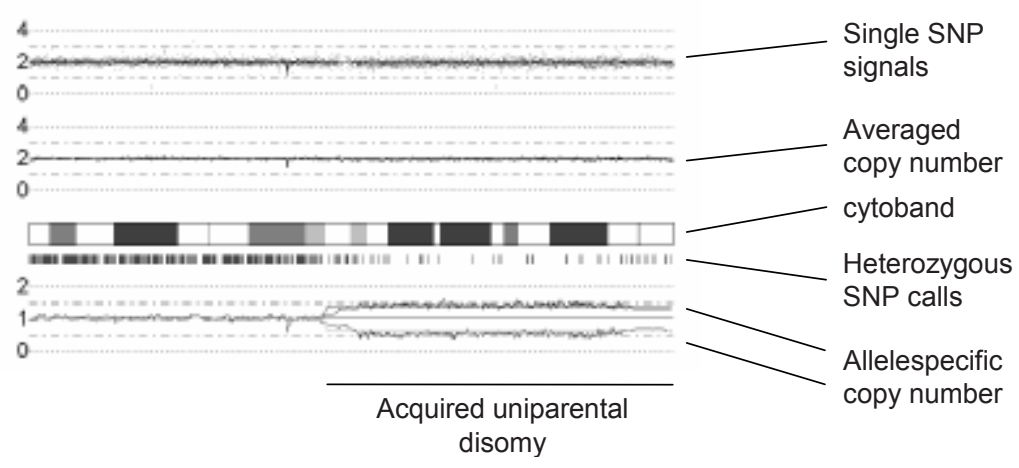

bined the power of genome-wide SNP array analysis and global gene expression assays and integrated the results. This approach allows investigators to pinpoint target genes with more interrogational power because often common genomic lesions detected by SNP arrays contain a large number of genes and it would be too laborious to analyze each potential gene. By searching for deregulated expression patterns of genes coded in the affected area by simultaneous gene expression microarray analysis, the number of candidate genes can be narrowed down considerably and has led to the discovery of interesting target genes associated with hematologic malignancies $[18,24,25]$ or solid tumors $[21,26]$.

\section{Application of SNP Arrays to Identify Common Traits of Complex Disease}

Besides the field of cytogenetics application, SNP arrays have become powerful tools in the search for genomic genotypes associated with or predisposing for certain phenotypes and diseases. As mentioned above, SNPs are polymorphic markers introduced into the genome by spontaneous germline mutation of single nucleotides. Although genomic diversity during human reproduction is maintained by genetic recombination during meiosis, chromosomal segments tend to be transmitted as blocks referred to as haplotypes [27-29]. This implicates that single genomic markers such as SNPs in a given haplotype can be used to predict the genotype of the surrounding region, which is described as linkage disequilibrium. This knowledge can be used to design studies, which link certain constellations of genotypes to specific diseases. Despite the fact that very large cohorts are needed to reach statistical significance in such association studies, they have been carried out for numerous common diseases such as coronary artery disease [30], diabetes and celiac disease [31, 32]. While such powerful association studies are very important first steps in creating a basis for predicting risks for certain diseases, they provide 


\section{Chromosome 9 in ALL}

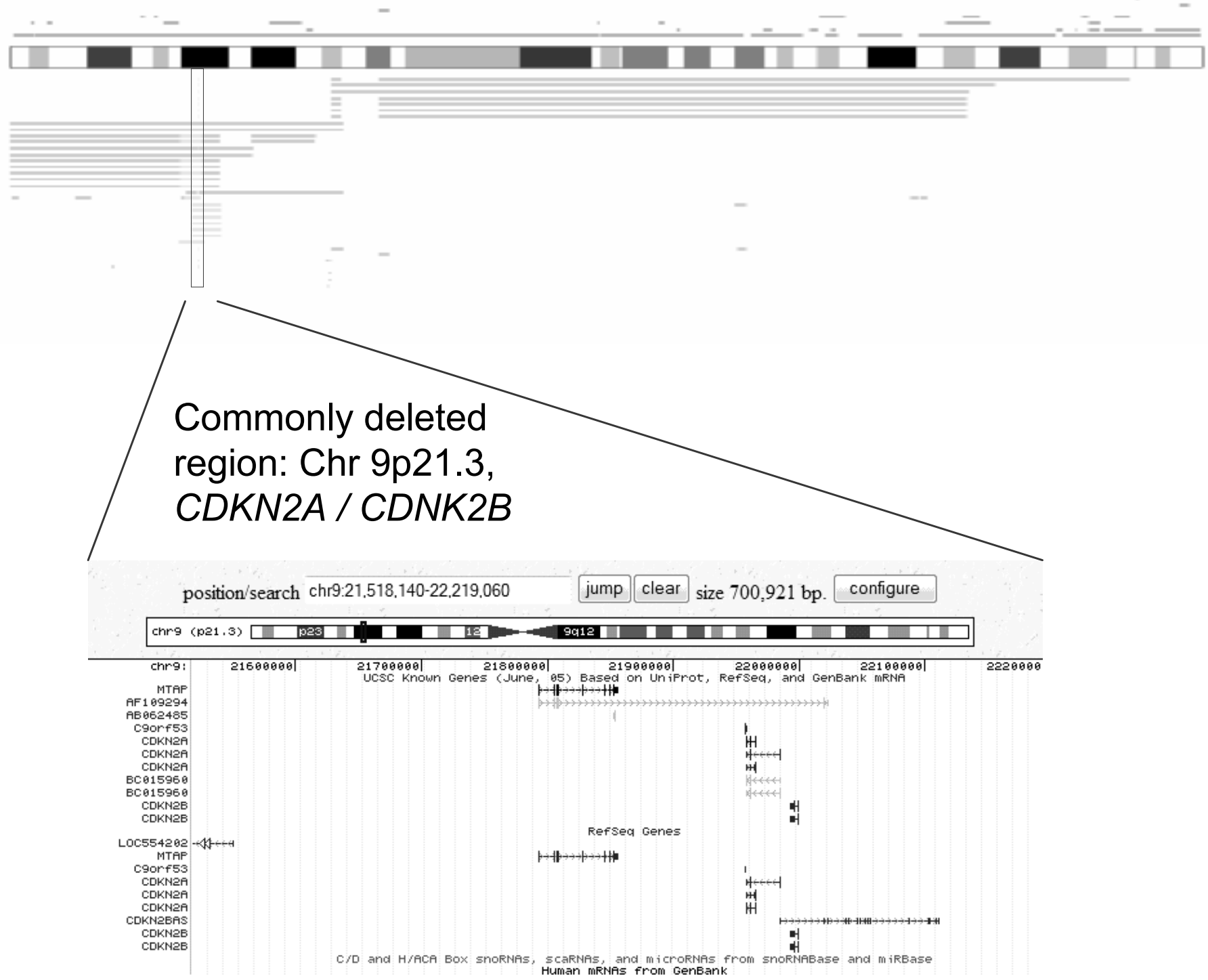

Fig. 3. Identification of target genes by identifying commonly affected genomic regions with the CNAG software. Shown is an integral view of chromosome 9 of a collection of ALL samples. Deletions are shown by horizontal lines below the cytoband, each line represents one sample. While many samples harbor big deletions, containing hundreds of potential target genes of the genomic lesion, overlapping the data from many samples leads to a reduction of size of the common region. This is impressively shown in ALL for hemi- and homozygous deletions pinpointing the tumor suppressor genes CDKN2A/CDKN2B or for the transcription factor Pax5.

little or no information about the functional aspects of the detected associations. Again, approaches which combine the power of whole genome association studies with other global screening methods go one step further. For example, studies which integrated data from association studies with expression quantitative trait loci determined by gene expression analysis and models of segregating mouse populations were not only able to determine the underlying trait loci of specific diseases, but also demonstrated the effects of the polymorphic constellations on gene function involved in the pathogenesis of the disease [33-35].

\section{Conclusion and Future Perspectives}

The rapidly developing technology for whole genome copy number analysis and genotyping with SNP arrays has permitted experimental researchers to elucidate genomic alterations and traits underlying multiple diseases. Until now, the technology has remained in the domain of research. However, SNP arrays have also enhanced prognostic systems and cytogenetic diagnostic procedures [7, 36]. Therefore, it is foreseeable, that SNP arrays will soon also gain relevance in routine cytogenetic examinations for determining prognosis 
or providing information for therapeutic decisions based on genotypes.

\section{Acknowledgment}

We thank the Parker Hughes Fund and National Institutes of Health grants for supporting our work. D.N. was supported by a research grant from the Deutsche Forschungsgemeinschaft (DFG, NO 817/1-1). H.P.K holds the Mark Goodson Chair in Oncology Research at Cedars Sinai Medical Center and is a member of the Jonsson Cancer Center and the Molecular Biology Institute of UCLA.

\section{Disclosure}

The authors declared no conflict of interest.

\section{References}

1 Botstein D, Risch N: Discovering genotypes underlying human phenotypes: past successes for mendelian disease, future approaches for complex disease. Nat Genet 2003;33:228-237.

2 Bacolod MD, Schemmann GS, Giardina SF, Paty P, Notterman DA, Barany F: Emerging paradigms in cancer genetics: some important findings from high-density single nucleotide polymorphism array studies. Cancer Res 2009;69:723-727.

>3 Redon R, Ishikawa S, Fitch KR, Feuk L, Perry GH, Andrews TD, et al: Global variation in copy number in the human genome. Nature 2006;444:444-454.

4 Dutt A, Beroukhim R: Single nucleotide polymorphism array analysis of cancer. Curr Opin Oncol 2007; 19:43-49.

5 Yamamoto G, Nannya Y, Kato M, Sanada M, Levine RL, Kawamata N, et al: Highly sensitive method for genomewide detection of allelic composition in nonpaired, primary tumor specimens by use of affymetrix single-nucleotide-polymorphism genotyping microarrays. Am J Hum Genet 2007;81:114-126.

6 Beroukhim R, Lin M, Park Y, Hao K, Zhao X, Garraway LA, et al: Inferring loss-of-heterozygosity from unpaired tumors using high-density oligonucleotide SNP arrays. PLoS Comput Biol 2006;2:e41.

7 Maciejewski JP, Mufti GJ: Whole genome scanning as a cytogenetic tool in hematologic malignancies. Blood 2008;112:965-974.

8 Mullighan CG, Downing JR: Genome-wide profiling of genetic alterations in acute lymphoblastic leukemia: recent insights and future directions. Leukemia 2009; doi: 10.1038/leu.2009.18.

$\checkmark$ O'Shea D, O'Riain C, Gupta M, Waters R, Yang Y, Wrench D, et al: Regions of acquired uniparental disomy at diagnosis of follicular lymphoma are associated with both overall survival and risk of transformation. Blood 2009;113:2298-2301.

10 Walker BA, Morgan GJ: Use of single nucleotide polymorphism-based mapping arrays to detect copy number changes and loss of heterozygosity in multiple myeloma. Clin Lymphoma Myeloma 2006; 186-191.

-11 Kawamata N, Ogawa S, Zimmermann M, Kato M, Sanada M, Hemminki K, et al: Molecular allelokaryotyping of pediatric acute lymphoblastic leukemias by high-resolution single nucleotide polymorphism oligonucleotide genomic microarray. Blood 2008;111:776-784.

12 Nowak D, Le Toriellec E, Stern MH, Kawamata N, Akagi T, Dyer MJ, et al: Molecular allelokaryotyping of T-cell prolymphocytic leukemia cells with high density single nucleotide polymorphism arrays identifies novel common genomic lesions and acquired uniparental disomy. Haematologica 2009;94:518-527.
13 Andersen CL, Wiuf C, Kruhoffer M, Korsgaard M, Laurberg S, Orntoft TF: Frequent occurrence of uniparental disomy in colorectal cancer. Carcinogenesis 2007;28:38-48.

14 Argos M, Kibriya MG, Jasmine F, Olopade OI, Su T, Hibshoosh H, et al: Genomewide scan for loss of heterozygosity and chromosomal amplification in breast carcinoma using single-nucleotide polymorphism arrays. Cancer Genet Cytogenet 2008;182: 69-74.

15 Haverty PM, Fridlyand J, Li L, Getz G, Beroukhim $\mathrm{R}$, Lohr S, et al: High-resolution genomic and expression analyses of copy number alterations in breast tumors. Genes Chromosomes Cancer 2008; 47 : 530-542.

16 Lin LJ, Asaoka Y, Tada M, Sanada M, Nannya Y, Tanaka Y, et al: Integrated analysis of copy number alterations and loss of heterozygosity in human pancreatic cancer using a high-resolution, single nucleotide polymorphism array. Oncology 2008;75: 102-112.

17 Harada T, Chelala C, Bhakta V, Chaplin T, Caulee K, Baril P, et al: Genome-wide DNA copy number analysis in pancreatic cancer using high-density single nucleotide polymorphism arrays. Oncogene 2008;27: 1951-1960.

18 Mullighan CG, Goorha S, Radtke I, Miller CB, Coustan-Smith E, Dalton JD, et al: Genome-wide analysis of genetic alterations in acute lymphoblastic leukaemia. Nature 2007;446:758-764.

19 Mullighan CG, Miller CB, Radtke I, Phillips LA, Dalton J, Ma J, et al: BCR-ABL1 lymphoblastic leukaemia is characterized by the deletion of Ikaros. Nature 2008;453:110-114.

20 Liu W, Xie CC, Zhu Y, Li T, Sun J, Cheng Y, et al: Homozygous deletions and recurrent amplifications implicate new genes involved in prostate cancer. Neoplasia 2008;10:897-907.

21 Garraway LA, Widlund HR, Rubin MA, Getz G, Berger AJ, Ramaswamy S, et al: Integrative genomic analyses identify MITF as a lineage survival oncogene amplified in malignant melanoma. Nature 2005; 436:117-122.

22 Baxter EJ, Scott LM, Campbell PJ, East C, Fourouclas N, Swanton S, et al: Acquired mutation of the tyrosine kinase JAK2 in human myeloproliferative disorders. Lancet 2005;365:1054-1061.

23 Kawamata N, Ogawa S, Zimmermann M, Niebuhr B, Stocking C, Sanada M, et al: Cloning of genes involved in chromosomal translocations by highresolution single nucleotide polymorphism genomic microarray. Proc Natl Acad Sci U S A 2008;105: 11921-11926.
4 Walker BA, Leone PE, Jenner MW, Li C, Gonzalez D, Johnson DC, et al: Integration of global SNPbased mapping and expression arrays reveals key regions, mechanisms, and genes important in the pathogenesis of multiple myeloma. Blood 2006;108: 1733-1743.

25 Nowak D, Nolte F, Mossner M, Nowak V, Baldus $\mathrm{CD}$, Hopfer O, et al: Genome-wide DNA-mapping of CD34+ cells from patients with myelodysplastic syndrome using 500K SNP arrays identifies significant regions of deletion and uniparental disomy. Exp Hematol 2009;37:215-224.

26 Lastowska M,Viprey V,Santibanez-Koref M,Wappler I, Peters $\mathrm{H}$, Cullinane $\mathrm{C}$, et al: Identification of candidate genes involved in neuroblastoma progression by combining genomic and expression microarrays with survival data. Oncogene 2007;26: $7432-7444$.

27 International HapMap Consortium: A haplotype map of the human genome. Nature 2005;437:1299-1320.

28 Sabeti PC, Varilly P, Fry B, Lohmueller J, Hostetter E, Cotsapas C, et al: Genome-wide detection and characterization of positive selection in human populations. Nature 2007;449:913-918.

29 Frazer KA, Ballinger DG, Cox DR, Hinds DA, Stuve LL, Gibbs RA, et al: A second generation human haplotype map of over 3.1 million SNPs. Nature 2007;449:851-861.

30 Samani NJ, Erdmann J, Hall AS, Hengstenberg C, Mangino M, Mayer B, et al: Genomewide association analysis of coronary artery disease. $\mathrm{N}$ Engl J Med 2007;357:443-453.

31 Gudbjartsson DF, Bjornsdottir US, Halapi E, Helgadottir A, Sulem P, Jonsdottir GM, et al: Sequence variants affecting eosinophil numbers associate with asthma and myocardial infarction. Nat Genet 2009; 41:342-347.

32 Smyth DJ, Plagnol V, Walker NM, Cooper JD, Downes K, Yang JH, et al: Shared and distinct genetic variants in type 1 diabetes and celiac disease. N Engl J Med 2008;359:2767-2777.

33 Chen Y, Zhu J, Lum PY, Yang X, Pinto S, MacNeil DJ, et al: Variations in DNA elucidate molecular networks that cause disease. Nature 2008;452:429-435.

34 Mehrabian M, Allayee H, Stockton J, Lum PY, Drake TA, Castellani LW, et al: Integrating genotypic and expression data in a segregating mouse population to identify 5-lipoxygenase as a susceptibility gene for obesity and bone traits. Nat Genet 2005;37:1224-1233.

35 Lusis AJ, Attie AD, Reue K: Metabolic syndrome: from epidemiology to systems biology. Nat Rev Genet 2008;9:819-830.

-36 Mullighan CG, Su X, Zhang J, Radtke I, Phillips LA, Miller CB, et al: Deletion of IKZF1 and prognosis in acute lymphoblastic leukemia. N Engl J Med 2009;360:470-480. 